\title{
The Evidence Based Design of Sun Dried Adobe Brick
}

\author{
Javeria Manzoor Shaikh \\ Indus Valley School of Art and Architecture Clifton, Karachi \\ Healthcare Lab, Hanyang University Korea \\ *Corresponding Author: javeria@hanyang.ac.kr
}

Copyright (C) 2014 Horizon Research Publishing All rights reserved.

\begin{abstract}
Martin Sauvage's book La brique et sa mise en oeuvre en Mésopotamie des origines à l'époque achéménide (1998) provided a comprehensive survey of brick in Ancient Mesopotamia. It measured the size of bricks and showed how they changed in format, looked at mortar types and bonding patterns at different sites and traced the use of fired bricks and sun-dried bricks. The Indus Civilisation flourished about the same time but no similar study has ever been carried out on its brickwork. This research aims to provide just such a study. The world today is facing depleting energy resources. For a country like Pakistan the case is even worse, where the gap between generation and consumption is constantly rising. Therefore, it is needed to efficiently utilize the scarce energy resources. Thus, the architects should pay attention to design and build such constructions that consume comparatively lesser amount of energy. The much acclaimed solution is the constructions of eco buildings. This research dresses the said issue.
\end{abstract}

Keywords Eco Brick, Sustainability, Lahore

\section{Introduction}

On one hand Pakistan is facing severe energy crises, and on the other the planet earth is going through global warming. The only solution for both is low carbon planning. The purpose of this dissertation is to show the benefit of low energy residential designs.

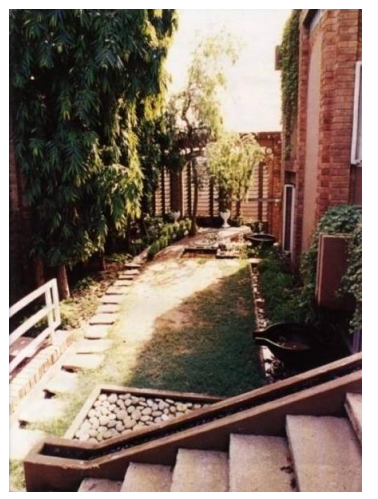

Figure 1. View from the entrance showing steps 1

\subsection{Dr. Shakeel Qureshi's House}

This house is functional, climate responsive, cost effective and aesthetically pleasing and falls into the category of good homes. The following are the most significant features:

This house on a small plot of $209 \mathrm{~m}^{2}$ has an accommodation of four bedrooms with all required facilities and yet has an area of $167 \mathrm{~m}^{2}$ (i.e. $80 \%$ of plot area) being green and landscaped as shown in figure 2 and $3 .{ }^{1}$

In the extreme weather conditions, it remains comfortable during summers where temperature rises to $46^{\circ} \mathrm{C}$ without any air-conditioner; and during winter's when the temperature drops to $0^{\circ} \mathrm{C}$, it remain under comfort zone without any heater.

Here economy is achieved in construction cost as well as in maintenance cost.

The house is aesthetically pleasing with interesting volumes and environment friendly materials as shown in figure 1 .

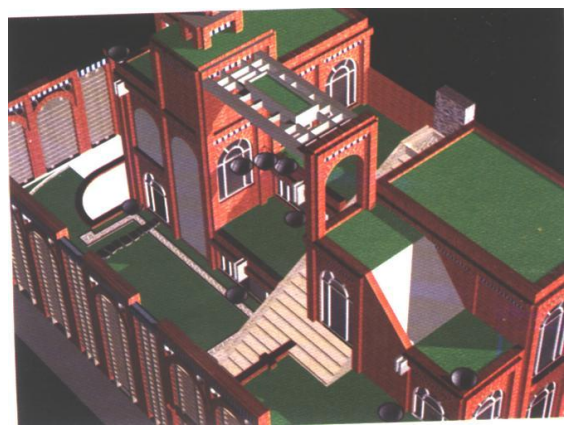

Figure 2. Axonometric ${ }^{1}$

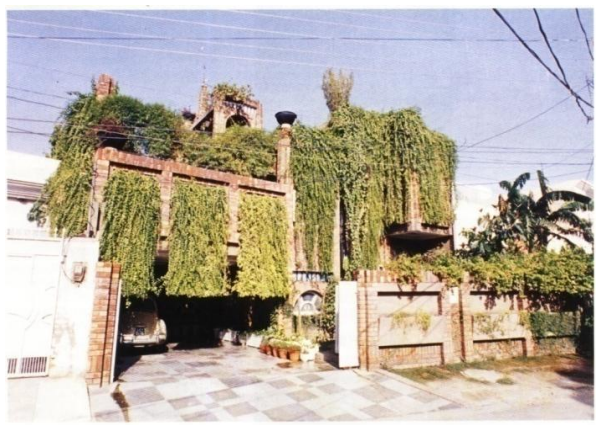

Figure 3. The outer view of the brick house 
Making the house an 'Energy Efficient' and ecological was not the only a challenge for the architect but making it 'Cost Effective' and low carbon was more of a big test for him as a construction manager. Generally the cost of construction comprises of two main components, i.e., cost of materials and cost of labor.

In this house, due to functional and aesthetic reasons, the best quality local materials and best available local craftsmen were used. The search for achieving economy in the cost of construction was done by economizing the quantities of materials which led the architect to work out details with less consumption of bricks, concrete and other materials.

\section{Materials and Methods}

This research will follow a similar format to Sauvage's study, tracing the brick's development from Indus Valley Civilisation, originally hand-moulded and sun-dried to moulded bricks and subsequently fired bricks. The research will start by mapping the sites and providing a detailed study of the archaeological reports for all the sites. Recording of bricks in archaeological reports tends to be mixed. The data from the reports will thus be supplemented by visiting each of the sites in turn and recording the sizes of bricks used, their manufacture and the way they are laid. By this method it will be possible to build up a very clear picture of the chronological development of the use of brick in the Ancient Indus Civilisation. This is important because the civilisation was one of the very earliest to use fired bricks and is thus believed to have had an influence on subsequent brickwork in other countries.

At the same time the study will look at the current state of the archaeological sites and compare them with previous photographs to assess the extent to which the site are suffering weathering and degradation (a problem frequently cited in the press) and look at the extent to which the sites have been damaged by theft and re-use of the materials.

The research would involve spending part of the $\mathrm{PhD}$ in Korea (reading the background material, meeting experts on Indus Valley Civilization culture and understanding the manufacture of brickwork etc) and some of the time in Pakistan doing field work (photographing, measuring and mapping of the brickwork).

\subsection{Technology and Design in the Brickwork at Indus Valley Civilisation}

\subsubsection{Survey and Analysis of the Buildings at Indus Valley Civilisation}

The objective is to collect information about Indus Valley Civilisation buildings brickwork (measured survey, graphic recording, archive research) and use them to analyse the tectonics.

\subsubsection{Buildings Description and History (Materials, Use, Tectonics, Overall Dimensions, Site)}

Furnishing the history as results from a direct reading of the fabric, or following archive research, and highlight: origins, design, original use, transformations

\subsubsection{Measure}

- Building plans with complete explanatory captions for the use of brickwork

- Elevation with explanatory captions for the use of brickwork

- Cross sections of walls showing the representative techniques and brickwork load-bearing characteristics

- Assess modularity and bond: a key characteristic of brick buildings

- Type of bricks (dimensions, fabricator, usage, durability)

\subsubsection{Tools}

- Measure modulus (blocks of bricks and mortar joints) and relate them to the overall elevation, as well as use the average to define the overall height of the elevation

- Definition of a datum line from the lowest brick course

- Drawing conventions and symbols to represent materials, changes, overlaying and structures to demarcate mixed brickwork in elevation and decorative elements (pediment, openings, doorway)

- Use photographs to complete any details. Take them from some distance to avoid distortions from perspective

\subsubsection{Analysis}

- Tectonics and Modularity

- Brick culture: discussions if locally, building practice is still followed and if there are common characteristics between the case studies.

- Brickwork: if there are different phases

- Case studies

If brick modules differ significantly, then statistical analysis will be performed to identify the average or distribution within the wall (it may indicate different chronology). The focus of the survey will be on the key elevations that with more openings, changes in the brickwork type and degradations.

\subsection{Background}

These bricks were made in abundant number over a period of decades, moulded out of the mud-clay extracted from the banks of river Indus and Chanab, serving as a building component to sculpt twin cities of Moen-Jo-Daro and Harappa. These bricks, shaped in a perfect dimensional ratio of $4: 2: 1$, which till today is considered best for the laying and planning of the bond.

This $\mathrm{PhD}$ research mainly aims to compile, and formulate, a complete manual for these Indus Valley civilisation brick, with accurate compositions, geometry, manufacture, and reuse, for the particularly designed modular brick and bonds, 
with unique and sustainable features. This brick was so perfect, that even centuries after its initial assembly, it was still an attractive building material for the construction contractors, few decades ago, and this is to note that today the railway linking Lahore to Multan in Pakistan is 4,600 years old.

\section{Brick ECO House in Lahore}

This plan at the upper level is more or less symmetrical, with stair case at the both side. There are more openings at the northern elevation as compared to the east, where there is harsh sun in the morning times. On the southern side there are more windows as compared to the east and west orientation. In figure 2.7 and 2.8 we can see the massing of the whole house; which is of orthogonal setting and the beautiful red brick combination with the green natural material.

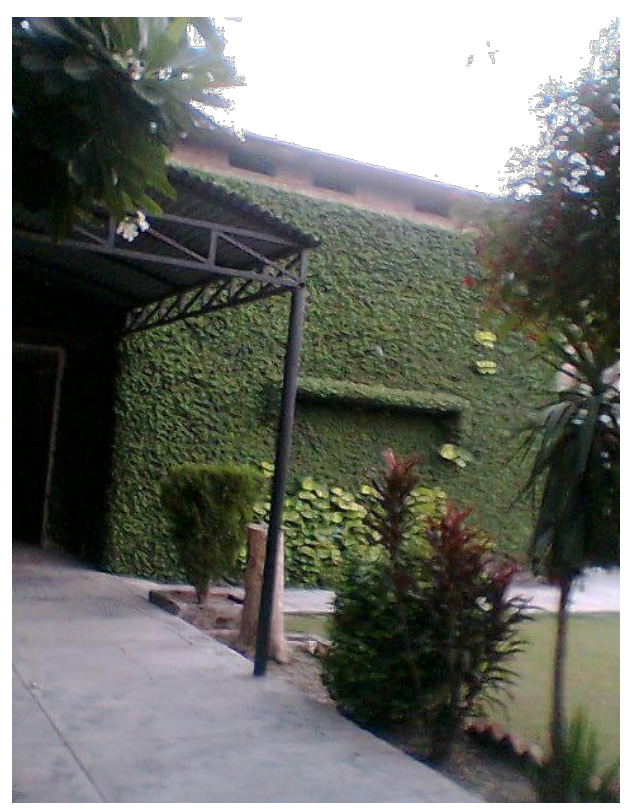

Figure 4. The house no. R-50

The house R-50 uses few passive techniques as shown in figure 4 for the prevention of sun radiation inside the house. This is directly affecting the consumption of the electricity. However, the drawback of this solution is that the green cover shown here invites a lot of insects and mosquitoes.

Simple techniques are used in the second house R-50 that resulted in radical reductions in the consumption of electricity. Figure 4; the section of the elevation; shows the creepers grown on the front elevation, which provide a natural insulation system for the latter house. The green screen shown in the figure 4.6; shows the huge fenestration of ten meter-square; provides a natural external curtain to prevent radiation. This also reduces the temperature of the house, because there is a continuous process of photosynthesis around the building. This provides natural ventilation and production of oxygen for the house. Consequently, it results in reduction of energy consumption.

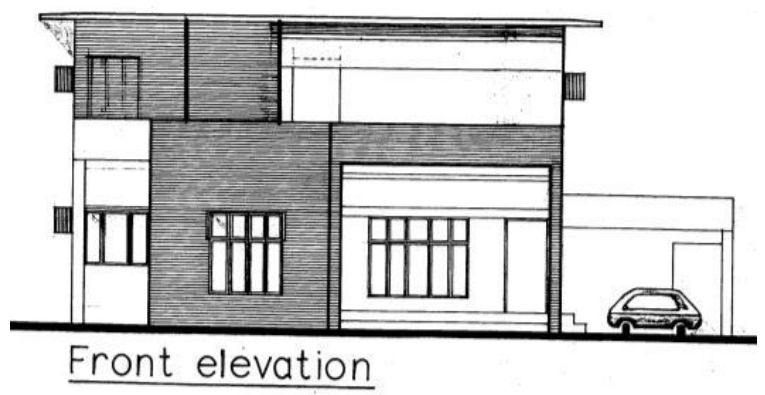

Figure 5. Entrance view ${ }^{1}$

Since the green roof is a visible expression of educating the ecological architecture for our environmental initiatives. Hence the author; herself an architect designer; is taking this idea. It is proposed by making a double façade so that the plants are not just on the roof but on the set of terraces; that wrap around the sun-exposed sides of the building.
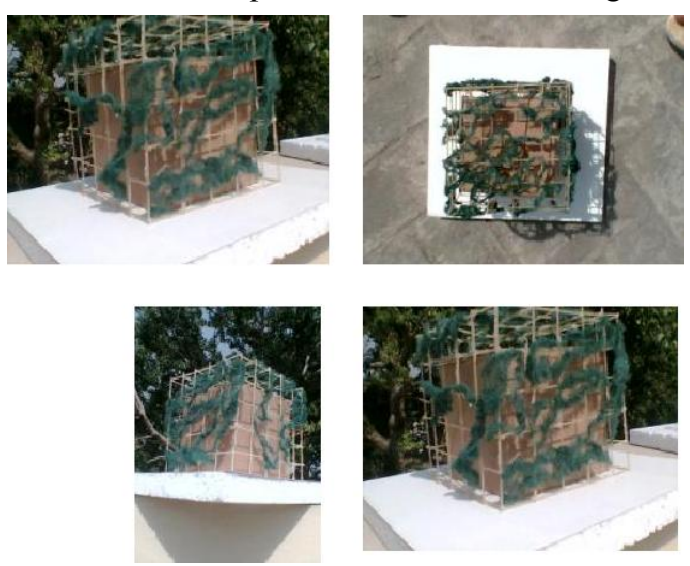

Figure 6. Double skin model

The figure. 6 shows the double skin used for the Eco House to prevent from the sun. Basically it is made up of replaceable and disposable bamboos that grow from the site. The reason of the double skin being independent of the house is to increase insulation, decrease humidification, improve aesthetics and to prevent insects from coming inside the house.

\subsection{Characteristics of the Brick}

- Intimate and enclosed at the private space

- Open airy and spacious areas for the public

- lesser noise

- No un pleasant smells

- Psychologically pleasing colors

- Presence of greenery and meso spaces (e.g. balcony)

- The work space should be open ${ }^{3}$

- (Open refers to not restricting the sight and linked with the outside environment)

Dr. Qureshi designed this house for his own family. Its lower level is public space, where there is drawing, dinning, kitchen, and guest bed. The figure 2. shows the plan of the private zone, where the bed rooms are located according to our cultural system. In this plan, half of the lower level is built, whereas the rest is landscaped, so that the occupants 
can have a good view from the window. The water channels used; to accelerate cold water circulation in winter; are also

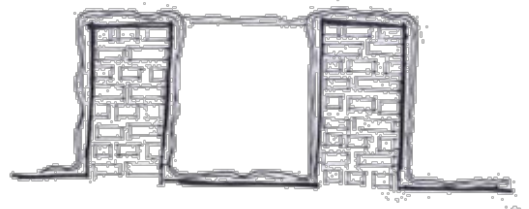

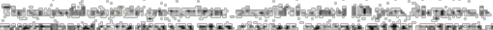
$23: 6$
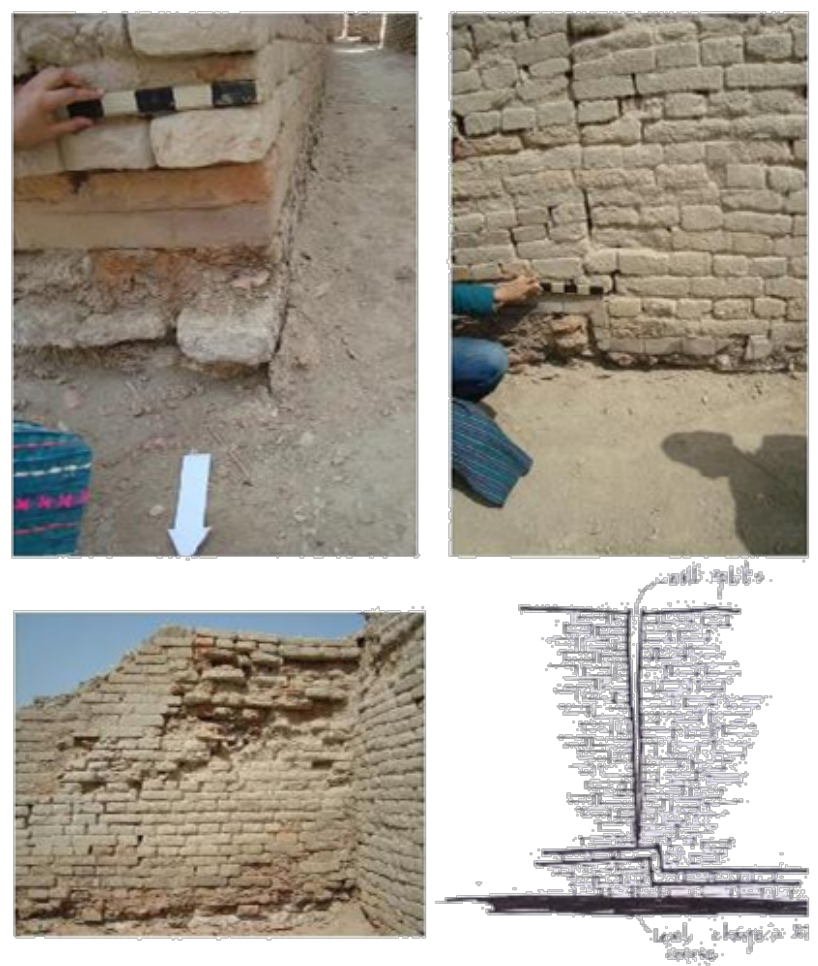

ใ.

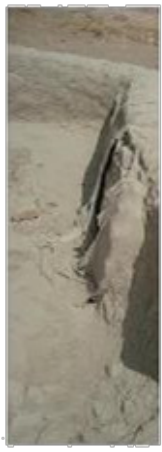

is shown here in the plan. This plan at the upper level is more or less symmetrical, with stair case at the both side.
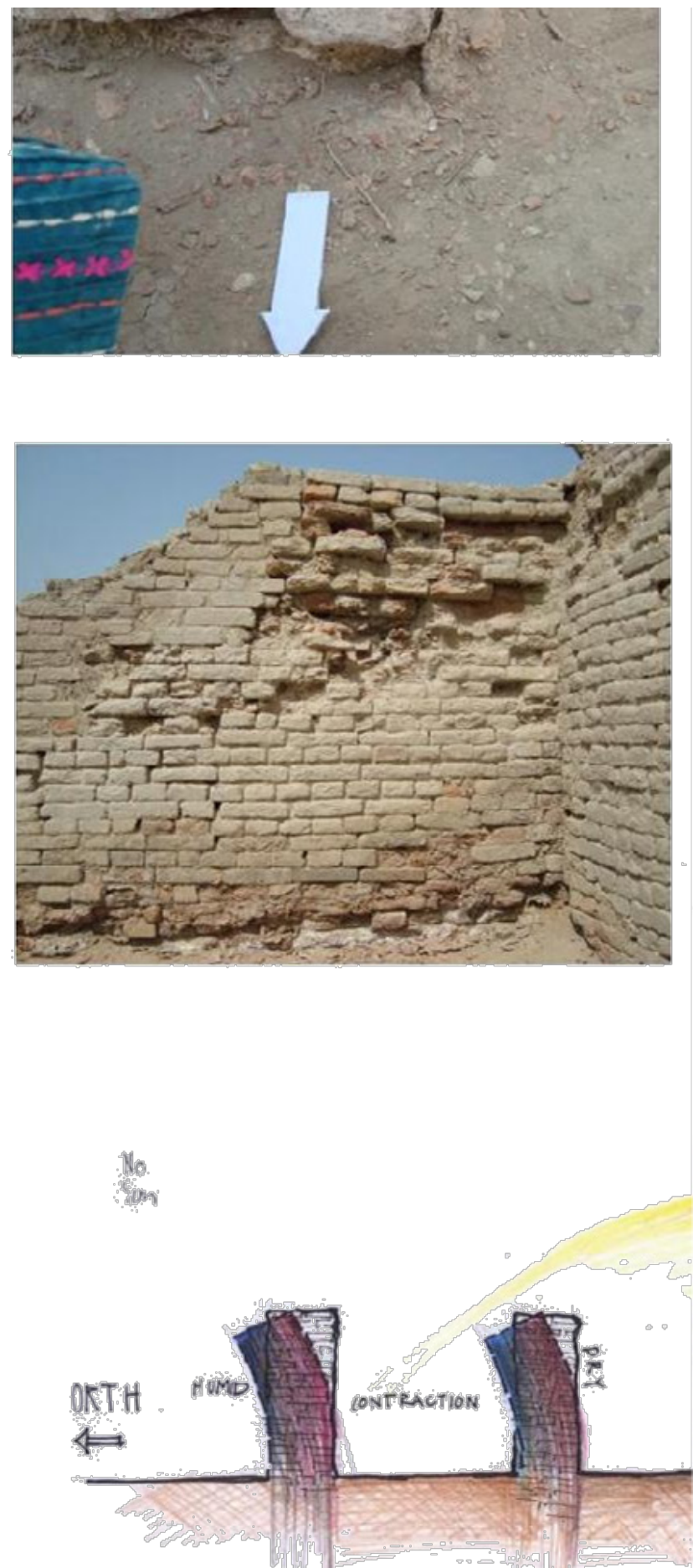

Figure 7. shows the ecological use of historical healthy brick sun dried 

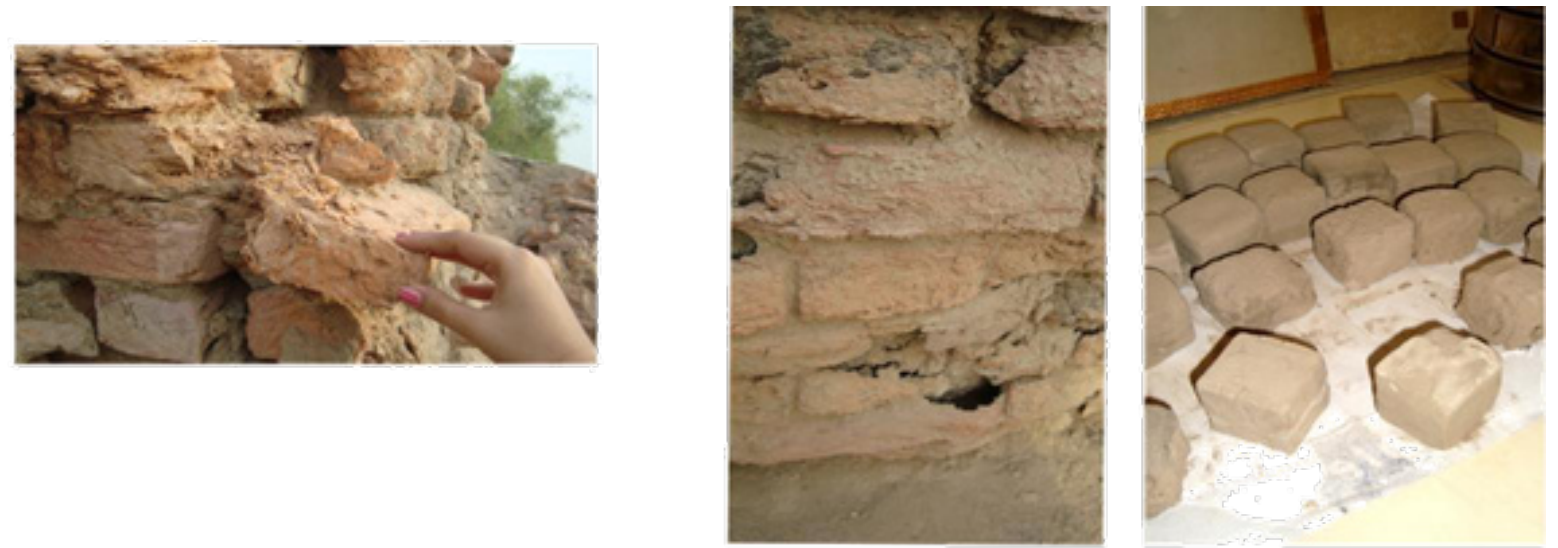

The experiment to have the silt free and salf free clay to prepare the mud slurry $4 \mathrm{X} 4$ inch cubes of clay were exposed to water with salt, the clay which absorbs minimum was chosen.

The clay was desolved in water, then filtered to funnel away any salt content.

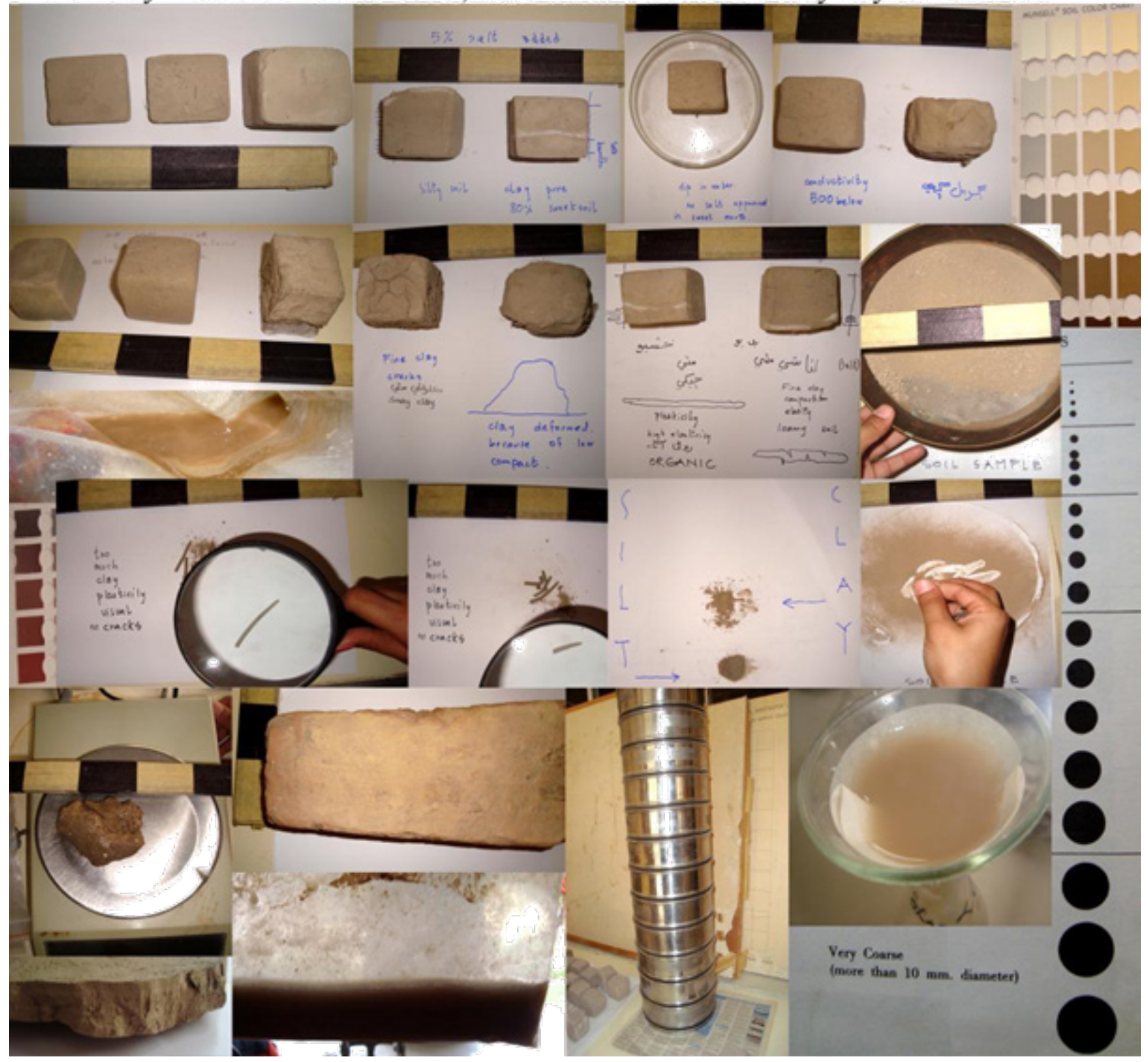

Figure 8. The brick and the healthy salt free adobe material in historic site 


\section{Conclusions}

This Eco brick should minimize the maintenance and use of the earth's resources namely, water, fossil fuel energy, materials; for the entire life of the building. Also because of the little maintenance it adopts slow building principles. Moreover, this house should be full of delight.

Any comments and suggestions are welcomed so that we can constantly improve this template to satisfy all authors' research needs.

ADAPT here refer to what else is like this, learn from nature.

MODIFY signifies change the meaning, size, color, direction.

MAGNIFY means make stronger, heavier, and more costly.

MINIFY refers to Miniaturize, omit, lighter, lower. SUBSTITUTE signifies that, what could be used instead?

Parts, Material, Power, Process.

REARRANGE refers to there an Alternative Design REVERSE means transposed, used in reverse upside down COMBINE refers to blend Ideas, Perform multiply functions $^{2}$

\section{REFERENCES}

[1] Dr. Shakeel Q, A+I Magazine; an interview, Archi times, Karachi, 1999, pp 74-86

[2] Ali Sodagaran, 4th Place, Mashriq, Competition for Eco House Oxford University 2004 from an Iranian Magazine, (in خانه الكولوز ىك،آلكسفورد,84-85. مسابقه

[3] Duran. S.C., Case Ecologiche, Modena, Italy, 2008, pp $105-115$

[4] Russell. F, Loblolly House: In Stock and Ready to Ship, Architectural Record, 2006, NY, http://ce.construction.com

[5] Antiquity act Pakistan 1975

[6] Sir John Marshall's Conservation Manual1922

[7] Esposito, D. (1998). Tecniche costruttive murarie medievali. From "Storia della tecnica edilizia e restauro dei monumenti". 